\title{
EFICÁCIA DOS DIREITOS FUNDAMENTAIS SOCIAIS E DAS LIBERDADES SOCIAIS
}

\author{
Silvia Teixeira do Vale ${ }^{148}$ \\ Maíra Guimarães de La Cruz ${ }^{149}$
}

RESUMO: Este trabalho analisa a eficácia dos direitos fundamentais sociais, bem assim as liberdades sociais, desmistificando a ideia segundo a qual somente aqueles são vinculados ao princípio da reserva do possível.

PALAVRAS-CHAVE: Direitos fundamentais sociais - eficácia - liberdades sociais.

ABSTRACT: This paper analyzes the effectiveness of fundamental social rights as well as social freedoms, demystifying the idea that only those are linked to the principle of the reserve of the possible.

KEYWORDS: Social fundamental rights - effectiveness - social freedoms.

SUMÁRIO: Introdução; 1. Breves notas sobre a evolução teórica acerca da eficácia das normas constitucionais; 2. Alcance do artigo $5^{\circ}, \S 1^{\circ}$ da Constituição Federal de 1988, à luz da máxima efetividade e da força normativa da Constituição; 3. Eficácia dos direitos sociais prestacionais e o problema da reserva do possível. Breves considerações; 4. Os direitos sociais prestacionais como direitos subjetivos; 5. As liberdades sociais; Conclusão; Referências.

SUMMARY: 1. Introduction; 2. Brief notes on theoretical developments regarding the effectiveness of constitutional norms; 3. Scope of article 5, paragraph 1 of the Federal Constitution of 1988, in the light of the maximum effectiveness and the normative force of the Constitution; 4. Effectiveness of social welfare rights and the problem of reserving the possible. Brief Considerations; 4. Prestational social rights as subjective rights; 6. social freedoms; 7. Conclusion; 8. References.

\footnotetext{
${ }^{148}$ Possui graduação em Direito pela Universidade Potiguar (1998), instituição esta onde se pós-graduou e foi professora durante seis anos. Professora convidada do curso de pós-graduação lato sensu da Faculdade Baiana de Direito, EMATRA5, CERS e da Escola Judicial do TRT da $5^{\text {a }}$ Região. Juíza do Trabalho no TRT da $5^{\text {a }}$ Região. Mestre em Direito pela UFBA. Doutora pela PUC/SP, pós-doutora pela Universidade de Salamanca, Membro do Conselho da Escola Judicial do TRT da $5^{\text {a }}$ Região (2012-2017). Coordenadora acadêmica da EMATRA5, biênio 2013/2015. Diretora da EMATRA5, biênio 2019/2021. Membro do Conselho editorial da Revista eletrônica do Tribunal Regional do Trabalho da Quinta Região e da Revista Vistos etc. Ex-professora substituta da UFRN.

${ }^{149}$ Juíza do Trabalho do TRT da 5a Região. Pós-Graduada em Direito Público pela Faculdade Jorge Amado/Jus Podivm.
} 


\section{Introdução}

Embora o artigo $5^{\circ}, \S 1^{\circ}$ do Texto Constitucional de 1988 seja enfático no sentido de se considerarem plenamente eficazes os Direitos Fundamentais, sem descurar em relação às gerações (ou dimensões) ou até mesmo no tocante aos particulares, a realidade tem demonstrado que isso não é suficiente, tendo-se que normas fundamentais há que, a despeito de exporem proteção a Direito Fundamental de suma importância para o bom desenvolvimento do Estado Democrático de Direito, ainda padecem de baixa densidade normativa, cabendo ao aplicador do Direito, sobretudo ao EstadoJuiz, compatibilizar a redação da norma com princípios como a força normativa da Constituição ou a plena eficácia de suas normas e a própria unidade do Texto Constitucional.

\section{Breves notas sobre a evolução teórica acerca da eficácia das normas constitucionais}

A discussão acerca da eficácia e alcance das normas constitucionais não é assunto moderno e, apesar da farta doutrina produzida, ainda padece de finalização terminológica segura e definitiva.

Foi Ruy Barbosa quem, partindo da doutrina e jurisprudência estadunidenses, primeiro tratou sobre o tema aqui no Brasil, dividindo as normas constitucionais em autoaplicáveis (ou autoexecutáveis) e normas não autoaplicáveis (ou não autoexecutáveis), assim entendidas pela doutrina estrangeira aludida, respectivamente, como normas self-executing, self-acting, ou self-enforcing e normas not self-executing, not self acting, ou not selfenforcing, ainda sob a égide da Constituição de 1891. Para o referido publicista, deve-se atentar para o enunciado ou conteúdo do preceito constitucional, para, a partir daí, se determinar se a correspondente norma é dirigida ao legislador ou ao judiciário, demonstrando que o mais importante a ser analisado é se a norma exige concretização ao patamar legislativo ou não, para gerar por si só efeitos jurídicos imediatos ${ }^{150}$.

${ }^{150}$ Cf. SARLET, Ingo Wolfgang. A eficácia dos direitos fundamentais. Op. cit., p. 242. 
José Afonso da Silva, sem abandonar completamente a divisão alhures apontada, dividiu as normas constitucionais em três grupos, a saber, normas de eficácia plena, de eficácia contida e de eficácia limitada. As primeiras são aquelas que não dependem de qualquer regulamentação do legislador ordinário, por serem completas, de aplicabilidade direta, integral e imediata, pois “desde a entrada em vigor da Constituição, produzem, ou têm possibilidade de produzir, todos os efeitos essenciais, relativamente aos interesses, comportamentos e situações, que o legislador constituinte, direta ou indiretamente, quis regular" ${ }^{151}$.

As segundas igualmente são aptas a gerar efeitos diretos, mas não integralmente, podendo ser limitadas pelo legislador ordinário, sendo "aquelas em que o legislador constituinte regulou suficientemente os interesses relativos à determinada matéria, mas deixou margem à atuação restritiva por parte da competência discricionária do poder público, nos termos que a lei estabelecer ou nos termos de conceitos gerais nelas enunciados" ${ }^{152}$.

Já as normas de eficácia limitada possuem eficácia reduzida, não sendo aplicáveis a partir do texto mesmo da Constituição, carecendo, necessariamente, de intervenção legislativa ordinária para que possam ser efetivamente aplicáveis, englobando tanto as normas declaratórias de princípios programáticos quanto as normas declaratórias de princípios institutivos e organizatórios $^{153}$.

Partindo do pressuposto segundo o qual todas as normas constitucionais, sobretudo as normas fundamentais constitucionais, mesmo com redação eivada de programaticidade ou que deixa transparecer necessária intervenção legislativa ordinária, são dotadas de eficácia, ainda que mínima, ao longo deste trabalho será adotada a ideia de Sarlet, que prefere falar em normas constitucionais de alta e baixa densidade normativa, sendo aquelas "aptas a, diretamente e sem intervenção do legislador, gerar os seus efeitos essenciais" e estas as que "não possuem normatividade suficiente para [...] gerar seus efeitos principais, ressaltando-se que, em virtude de uma normatividade mínima

\footnotetext{
${ }^{151}$ SILVA, José Afonso da. Aplicabilidade das Normas Constitucionais. 7. ed., São Paulo: Malheiros, 2007, p. 79.

152 SILVA, José Afonso da. Op. cit., p. 79.

${ }^{153}$ SILVA, José Afonso da. Op. cit., p. 73 e 106.
} 
(presente em todas as normas constitucionais), sempre apresentam certo grau de eficácia jurídica" ${ }^{154}$.

Todavia, não há como ignorar o fato de que a técnica legislativa adotada para confecção e positivação dos Direitos Fundamentais importa necessariamente na eficácia deles, sem deixar de lado o quanto já afirmado em relação à mínima eficácia consagrada em todas as normas jusfundamentais, ainda que sejam programáticas.

Doutra banda, não se pode igualmente ignorar o fato de que determinados Direitos Fundamentais já foram positivados "como autênticas ordens de legislar"155, ou, como prefere Canotilho, como "normas impositivas" ${ }^{156}$, sendo certo que já nesse momento se pode afirmar com exatidão que a proteção em face da despedida arbitrária, objeto do presente trabalho, constitui-se em norma impositiva, contendo em si o artigo $7^{\circ}$, I da CRFB/88 uma ordem dirigida diretamente ao Legislador, impondo que este exercite o seu múnus e crie normas jurídicas protetivas ao emprego, sobretudo traçando diretrizes indenizatórias no tocante à denúncia vazia do contrato de trabalho, conforme já prevê do indigitado dispositivo constitucional.

Em relação à multifuncionalidade atinente aos Direitos Fundamentais, estes são classicamente divididos em direitos de defesa, assim compreendidos como os direitos que tratam de liberdade, igualdade, políticos e garantias fundamentais; e os direitos a prestações, modernamente subdivididos em direitos a prestações em sentido amplo (proteção e participação na organização e procedimento) e direitos a prestações em sentido estrito, como os direitos sociais vinculados à prestação material, sendo certo que se, em relação aos direitos de defesa, habitualmente não há maiores discussões acerca da sua eficácia imediata, não se pode afirmar o mesmo no tocante aos direitos a prestações, passíveis de forte divergência doutrinária em relação à sua eficácia, já que requerem uma intervenção estatal material e legislativa positiva, questões estas não resolvidas somente pela leitura do artigo $5^{\circ}, \S 1^{\circ}$ da Constituição

${ }^{154}$ SARLET, Ingo Wolfgang. A eficácia dos direitos fundamentais. 10. ed., Porto Alegre: Livraria do Advogado, 2008, p. 252.

${ }^{155}$ SARLET, Ingo Wolfgang. A eficácia dos direitos fundamentais. 10. ed., Porto Alegre: Livraria do Advogado, 2008, p. 259.

${ }^{156}$ CANOTILHO, J. J. Gomes. Direito Constitucional e Teoria da Constituição. 5. ed., Coimbra: Almedina, 2002, p. 1240. 
pátria, em que pese a sua importante e inovadora previsão quanto à plena e imediata eficácia das normas tratantes de Direitos Fundamentais.

\section{Alcance do artigo $5^{\circ}, \S 1^{\circ}$ da Constituição Federal de 1988, à luz da máxima efetividade e da força normativa da Constituição}

No dizer de Canotilho, o princípio da máxima efetividade, também chamado de princípio da eficiência ou princípio da interpretação efetiva, significa que: "a uma norma constitucional deve ser atribuído o sentido que maior eficácia lhe dê" ${ }^{157}$, sendo sempre e atualmente invocado para se resolver questões constitucionais difíceis, em caso de dúvida acerca do alcance e interpretação de determinado preceito constitucional.

Outro princípio bastante festejado é o da força normativa da Constituição, que pode até aparentar obviedade diante da sua autoexplicabilidade, mas é fruto de imenso avanço científico e mudança paradigmática na hermenêutica constitucional da segunda metade do século passado, tendo-se que, até então, os países ocidentais de orientação romanogermânica seguiam diretriz interpretativa sem grandes questionamentos em relação às limitações do Poder Legislativo, o que levava à compreensão segundo a qual a Constituição era um mero documento político, desconstituído de força normativa ampla, contendo normas inferiores às ordinariamente confeccionadas.

Seguindo método intitulado de hermenêutico concretizador, Konrad Hesse tratou da Constituição jurídica, que, em síntese, deve guardar simetria com os valores sociais de seu tempo chamada de Constituição real; caso contrário, servirá de elemento catalisador para conflito, “cujo desfecho há de verificar contra a Constituição escrita, esse pedaço de papel que terá de sucumbir diante dos fatores reais de poder dominantes no país" ${ }^{158}$. O citado publicista também afiançou que a Constituição se converterá em "força ativa se fizerem presentes, na consciência geral - particularmente, na consciência dos

\footnotetext{
157 Op. cit., p. 1.208.

${ }^{158}$ HESSE, Konrad. A força normativa da Constituição. Tradução de Gilmar Ferreira Mendes. Porto Alegre: Sergio Antonio Fabris Editor, 1991, p. 9.
} 
princípios responsáveis pela ordem constitucional - não só a vontade de poder, mas também a vontade de constituição" ${ }^{159}$ (grifos no original).

Para Canotilho, o princípio hermenêutico da força normativa da Constituição quer dizer que "na solução dos problemas jurídico-constitucionais deve dar-se prevalência aos pontos de vista que, tendo em conta os pressupostos da constituição, contribuem para uma eficácia óptima da lei fundamental”. Nesse trilhar, "deve dar-se primazia às soluções hermenêuticas que, compreendendo a historicidade das estruturas constitucionais, possibilitam a 'actualização' normativa, garantindo, do mesmo pé, a sua eficácia e permanência" 160 .

Esse também parece ser o entendimento de Bandeira de Melo, quando salienta que o Direito tem como nota típica a imposição de conduta, sendo o regramento constitucional "um conjunto de dispositivos que estabelecem comportamentos obrigatórios para o Estado e para indivíduos", não sendo as normas constitucionais meros convites à legislação, opções ideológicas sem conteúdo normativo, ainda que encerrem preceito programático, pois "não há norma constitucional alguma destituída de eficácia" e todas as normas constitucionais "irradiam efeitos jurídicos, importando sempre numa inovação da ordem jurídica preexistente a entrada em vigor da Constituição a que aderem e a ordenação instaurada" ${ }^{161}$.

$\mathrm{O}$ artigo $5^{\circ}, \S 1^{\circ}$ do Texto Constitucional pátrio, instituindo que "as normas definidoras dos direitos fundamentais têm aplicabilidade imediata", foi fortemente inspirado no artigo 18/1 da Constituição portuguesa de 1976 e no artigo $1^{\circ}$, III da Lei Fundamental de Bonn, que tratam também da eficácia dos Direitos Fundamentais ${ }^{162}$; mas, embora possa se retirar do seu conteúdo um certo perfume dos princípios da máxima efetividade das normas constitucionais e da força normativa da Constituição, a simples leitura não é suficiente para determinar o seu real alcance, tendo-se que o problema da eficácia das normas

\footnotetext{
${ }^{159}$ Op. cit., p. 19.

160 Op. cit., p. 1.210.

${ }^{161}$ MELLO, Celso Antônio Bandeira de. Eficácia das normas constitucionais e direitos sociais. 1. ed., $3^{\mathrm{a}}$ tiragem, São Paulo: Malheiros, 2011, p. 13.

162 Artigo 18/1 da Constituição portuguesa de 1976: “os preceitos constitucionais respeitantes aos direitos, liberdades e garantias são diretamente aplicáveis e vinculam as entidades públicas e privadas”. Artigo $1^{\circ}$, III da Lei Fundamental alemã: "os direitos fundamentais a seguir enunciados vinculam o Legislador, o Poder Executivo e o Judiciário como direito diretamente vigente".
} 
jusfundamentais, como já detectado ao norte, é resolvido muito mais prestandose atenção à técnica utilizada pelo Legislador Constituinte, atentando-se para a baixa ou alta densidade normativa de cada dispositivo, do que pela aplicação cega do preceito indigitado.

Como bem disposto por Sarlet ${ }^{163}$, as teses a respeito do alcance do artigo $5^{\circ}, \S 1^{\circ}$ da nossa Constituição podem ser bipolares, havendo os que acreditam que o mandamento constitucional é suficiente para resolver o problema da eficácia dos direitos fundamentais, sendo a mesma plena e imediata ${ }^{164}$, ante o dispositivo constitucional, e os que, ao revés, fundamentam que o Legislador, ao estabelecer tal regramento, disse além do que desejava, cabendo ao intérprete conter a sanha ampliativa em um primeiro momento conduzida pelo artigo constitucional ${ }^{165}$.

Especificamente no tocante aos direitos de defesa, não há qualquer dissenso doutrinário em relação à sua plena e automática aplicabilidade. Assim, é correto dizer que todos os direitos de defesa são autoaplicáveis, por conta da técnica de redação empregada e, também, por encerrarem direitos absenteístas, cabendo ao Estado ou até mesmo aos particulares se absterem de perpetrar determinada conduta libertária, o que não impede sejam os mesmos direitos defensivos tidos no sentido prestacional, como sói ocorrer com os direitos políticos, que primariamente encerram direitos de defesa, mas também requerem por parte do Estado conduta prestacional no sentido do fornecimento do aparato necessário para a livre fruição do direito de sufrágio.

Se é certo que, em relação a todas as normas constitucionais, pende a presunção de máxima eficácia, justamente em face do princípio de terminologia idêntica, em se tratando de Direitos Fundamentais, a presunção de plena e imediata eficácia é ainda maior, sendo ainda mais correto afirmar que tais possuem um plus eficacial capaz de gerar tal presunção, por força do princípio presente no artigo $5^{\circ}, \S 1^{\circ}$ da nossa Constituição. Mas tal afirmação,

\footnotetext{
163 Op. cit., p. 263 e ss.

${ }^{164}$ Nesse sentido, é a doutrina de Grau, para quem "o preceito inscrito no $\S 1^{\circ}$ do art. $5^{\circ}$ da Constituição de 1988 afirma a aplicação imediata das normas definidoras de direitos e garantias fundamentais. Isso significa que tais normas devem ser imediatamente cumpridas pelos particulares, independentemente da produção de qualquer ato legislativo ou administrativo. Significa, ainda que o Estado também deve prontamente aplicá-las, decidindo pela imposição do seu cumprimento, independentemente da produção de qualquer ato legislativo ou administrativo, e as tornando jurídica e formalmente efetivas" (GRAU, Eros Roberto. A ordem econômica na Constituição de 1988. 15. ed., São Paulo: Malheiros, 2012, p. 318).

${ }^{165}$ Esse é, em síntese, o pensamento de Gebran Neto, citado por Sarlet (Op. cit., p. 264).
} 
como já aludido, por si só não resolve o problema, sendo certo que somente a análise tópico-sistemática das normas jusfundamentais aplicáveis ao caso concreto, atrelada à interpretação evolutiva e à observância da densidade normativa de cada específico direito fundamental será hábil a ensejar o seu real alcance.

Apesar da sedutora tese de que o artigo $5^{\circ}, \S 1^{\circ}$ da Constituição pátria contém determinação no sentido de se considerarem todas as normas que tratam de Direitos Fundamentais já autoaplicáveis, parece que novamente a razão está na temperança de Sarlet, para quem o aludido dispositivo constitucional encerra conteúdo principiológico no sentido proposto por Alexy, sendo mandamento de otimização, devendo o aplicador do Direito e todos os órgãos estatais, quando em dúvida acerca do alcance do Direito Fundamental, dar-lhe a maior eficácia possível, pois o "postulado da aplicabilidade imediata não poderá resolver-se, a exemplo do que ocorre com as regras jurídicas, de acordo com a lógica do tudo ou nada, razão pela qual o seu alcance dependerá do exame da hipótese em concreto, isto é, da norma de direito fundamental em pauta"166, ou, em outras palavras, pela técnica da ponderação de interesses constitucionalmente assegurados.

\section{Eficácia dos direitos sociais prestacionais e o problema da reserva do possível.}

\section{Breves considerações}

Os direitos de defesa, como já mencionado, por requisitarem apenas uma atitude abstencionista (deixando de lado, evidentemente, a sua versão positiva) por parte do Estado ou dos particulares, normalmente não encontram divergência na doutrina ${ }^{167}$ em relação à sua plena eficácia, realidade sempre corroborada com a afirmação de que tais direitos não dependem de grande dispêndio estatal, não se vinculando sequer ao denominado princípio da reserva do possível.

A tese não se sustenta quando se verifica que diversos direitos capitulados como defensivos necessitam de forte amparo e dispêndio estatal,

166 Op. cit., p. 270.

${ }^{167}$ Cf. SARLET, Ingo Wolfgang. Eficácia dos Direitos Fundamentais. Op. cit. p. 280. 
como sói ocorrer nas eleições, conforme ao norte analisado, ou até no próprio direito de propriedade, que requer o acionamento do Poder Judiciário e grande apelo policial para sua fiel defesa, gerando, por conseguinte, um custo, o que demonstra que tal afirmação figura mais como um sofisma do que como uma realidade, tendo-se que todos os direitos fundamentais são custosos ao Estado.

Nesse trilhar, como afirma Gustavo Amaral, "todos os direitos têm custos porque todos pressupõem o custeio de uma estrutura de fiscalização para implementá-los"168 e, corroborando a tese, a lição de Sarlet, para quem todos os direitos fundamentais "são, de certo modo, sempre direitos positivos, no sentido de que também os direitos de liberdade exigem um conjunto de medidas positivas por parte do poder público, que abrangem a alocação significativa de recursos materiais e humanos para a sua proteção e implementação" 169 .

Nunca é demais frisar que o Estado, quando resolveu tomar para si a tutela jurisdicional, afastando a possibilidade de autotutela, criou a necessidade de custeio com o sistema carcerário e policial para impedir a tortura e o exercício arbitrário do ofendido, e quase ninguém ignora que essa opção pela paz na sociedade através do monopólio estatal desencadeia um imenso dispêndio - mesmo que isso diga respeito aos "primeiros direitos fundamentais" -, mas isso, como é da cultura constitucional, não é questionado e posto como impedimento para a segurança de todos os cidadãos.

Outra grande argumentação em prol da plena eficácia dos direitos de defesa reside no fato de que estes têm como desiderato a limitação de poder, estatal ou particular, ao passo que os direitos sociais a prestações, por almejarem a igualdade, necessitam de atitude positiva por parte do Estado (ou até dos particulares), para que o princípio da isonomina na sua visão material seja alcançado plenamente.

Isso porque todos os direitos sociais prestacionais - como, por exemplo, habitação, saúde e educação -, assim entendidos como direitos positivos e estimulados pelo Estado por obrigação constitucional, visam a assegurar, através de uma desigualdade jurídica, a plena igualdade material, tendo-se que o contrário da igualdade não é a desigualdade, mas, sim, a própria

\footnotetext{
168 AMARAL, Gustavo. Direito, Escassez \& Escolha. Critérios Jurídicos para Lidar com a Escassez de Recursos e as Decisões Trágicas. 2. ed. Rio de Janeiro: Renovar, 2010, p. 39.

${ }^{169}$ Op. cit., p. 285.
} 
igualdade, somente alcançada através de uma política de inserção social justa ${ }^{170}$, daí a necessidade de intervenção estatal positiva nas relações sociais e na economia, para o usufruto da liberdade concreta, não abstrata e formal, maior objetivo de todos os direitos fundamentais.

Apesar do quanto afirmado, aderindo à tese de plena eficácia dos direitos de defesa, é possível se vislumbrar uma visão negativa dos direitos sociais prestacionais, assim entendidos como os direitos à organização e procedimento desses mesmos direitos, ou até mesmo a necessidade de o Estado não intervir na prestação já concedida - fato que se liga diretamente à própria vedação ao retrocesso social -, vicissitudes que, por ora, não serão exploradas.

Sem embargo, enquanto os custos dos direitos sociais prestacionais são apontados como o grande entrave da sua efetivação material, os custos pertinentes aos direitos de defesa são normalmente desprezados, até culturalmente, tendo-se que classicamente os direitos defensivos são tidos como "naturais" e inatos ao ser humano, pois historicamente o Estado somente se preocupava em assegurar a liberdade em seu sentido formal, abstendo-se de intervir nas relações privadas e na economia para assegurar a igualdade.

Com a chegada do Estado Social, essa realidade estatal abstencionista se mostrou insuficiente, redundando no questionamento acerca dos dividendos estatais, pois as prestações sociais costumam ser mais dispendiosas do que o aparato estatal necessário para viabilizar os direitos de defesa, o que ocasionou a vinculação tão somente dos direitos sociais prestacionais à "reserva do possível"171, assim entendida como "aquilo que o indivíduo pode exigir da sociedade", conforme decidido pelo Tribunal Constitucional alemão, no julgado $B \operatorname{Verf} G E, 33^{172}$.

\footnotetext{
${ }^{170}$ Nesse sentido: "Enquanto nos outros valores (justiça, segurança, liberdade) a polaridade significa o momento da sua negação (injustiça, insegurança, falta de liberdade), na igualdade o seu oposto não a nega, senão que muitas vezes a afirma. Aí está o paradoxo da igualdade. A desigualdade nem sempre é contrária à igualdade" (TORRES, Ricardo Lobo. Os direitos humanos e a tributação: imunidades e isonomia. Rio de Janeiro: Renovar, 1995, p. 261-262).

${ }^{171}$ A reserva do possível pode ser tida no sentido jurídico, cabendo ao Estado-Legislador decidir acerca da viabilidade da confecção de leis para tratar do respectivo direito social prestacional; e fático, assim entendido como a provisão de numerário nos cofres públicos, resolvida, em um primeiro plano, pelos Poderes Legislativo e Executivo.

${ }^{172} \mathrm{Na}$ oportunidade, a Corte alemã analisou demanda judicial proposta por estudantes que não haviam sido admitidos em escolas de medicina de Hamburgo e Munique em face da política de limitação do número de vagas em cursos superiores adotada pela Alemanha em 1960. A pretensão foi fundamentada no artigo 12 da Lei Fundamental daquele Estado, segundo a qual "todos os alemães têm direito a escolher livremente sua profissão, local de trabalho e seu centro de formação". Ao decidir a questão, o Tribunal Constitucional
} 
Refutando uma distinção forte entre os direitos de liberdade e os direitos sociais no plano da reserva do possível, tendo-se que ambos os direitos possuem custos e, por tal razão, a argumentação não pode servir de fundamento para a não eficácia dos direitos sociais prestacionais, Novais ainda lembra que alguns direitos sociais prestacionais, entendidos sob a sua vertente negativa, não custam nada, como "os deveres estatais de respeitar ou não impedir o acesso a cuidados de saúde pagos pelos próprios particulares (integráveis no direito social à saúde com um todo)" ${ }^{173}$, sendo mais correto se falar em contraponto da reserva do possível à dimensão principal de cada direito, tendo-se que, "por força de sua natureza, os direitos sociais são [na dimensão positiva] juridicamente condicionados pela reserva do possível"174.

É saber, a reserva do possível é argumento limitador imanente aos direitos sociais prestacionais na opinião do referido autor, por serem tais sempre vinculados a uma necessária fonte de custeio e, pela própria natureza, custarem mais caro ao Estado. A razão, no entanto, parece estar novamente com Sarlet, quando este argumenta que a afirmação de que a reserva do possível é elemento integrante dos direitos fundamentais é equivocada, "como se fosse parte do seu núcleo essencial ou mesmo como se estivesse enquadrada no âmbito do que se convencionou denominar de limites imanentes dos direitos fundamentais" ${ }^{175}$, porquanto a reserva do possível, enquanto argumentação em torno da escassez de recursos, é critério artificialmente criado pelos intérpretes das Constituições, podendo servir tanto para conceder ou negar um determinado direito fundamental, quando com outro conflitante.

A ideia de vinculação ou justiciabilidade ${ }^{176}$ dos direitos sociais prestacionais aos custos correlatos cai por terra quando se percebe que o Estado

\footnotetext{
entendeu que o direito à prestação positiva - no caso aumento do número de vagas na universidade - encontrase sujeito à reserva do possível, no sentido daquilo que o indivíduo pode esperar, de maneira racional, da sociedade. Ou seja, a argumentação adotada refere-se à razoabilidade da pretensão.

173 NOVAIS, Jorge Reis. Direitos sociais. Teoria jurídica dos direitos sociais enquanto direitos fundamentais. Coimbra: Coimbra Editora, 2010, p. 97.

${ }^{174}$ NOVAIS, Jorge Reis. Op. cit., p. 101.

175 Op. cit., p. 288.

176 “Por 'justiciabilidade' entende-se a possibilidade de o titular do direito reclamar perante o juiz ou tribunal o cumprimento das obrigações que derivam desse direito. Nesse sentido, ser titular de um direito subjetivo significa deter um poder jurídico reconhecido pelo direito objectivo, isto é, deter o poder de participar na criação de uma norma individual por intermédio de uma acção específica em justiça, designadamente através de reclamação ou queixa" (QUEIROZ, Cristina M. M. Direitos fundamentais sociais. Funções, âmbito, conteúdo, questões interpretativas e problemas de justiciabilidade. Coimbra Editora, 2002, p. 148).
} 
às vezes pode despender mais numerário com os direitos de defesa, como sói ocorrer quando uma vítima de tortura recebe indenização, ou um proprietário ingressa na Justiça e tem o seu pleito indenizatório aceito, diante da constatação de desapropriação indireta, custos normalmente muito mais elevados do que o fornecimento de determinados remédios ou mesmo uma habitação digna.

Novais aponta o caminho a ser percorrido:

tomados como um todo, encontramos nos dois tipos de direitos modalidades de afectação pela reserva do possível. Há, no entanto, uma diferença sensível. Enquanto os bens de liberdade e de autonomia jusfundamentalmente protegidos pelos direitos de liberdade não custam (por exemplo, liberdade de religião, de expressão, de manifestação, de associação, de greve, não custam, não é possível comprá-las no mercado), então, em princípio, a reserva do financeiramente possível não os afecta intrinsecamente; só os afecta relativamente aos deveres estatais destinados a promover o acesso individual a esses bens ou a garantir a sua efetividade prática através da criação de institutos, procedimentos, serviços, apoios ou compensações. Diferentemente, como os bens jusfundamentalmente protegidos pelos direitos sociais são bens escassos, custosos, procuráveis no mercado, então a reserva do financeiramente possível, em geral, afecta-os intrinsecamente; só não os afecta relativamente aos deveres estatais de respeito e não impedimento do acesso a esses bens por parte dos particulares que dispõem, por si mesmos, dos correspondentes recursos próprios para garantir o acesso.

Se se tomar, todavia, como pressuposto que a Constituição é um sistema aberto de regras e princípios e que os Direitos Fundamentais (de defesa ou prestacionais) são princípios, assim entendidos como mandamentos de otimização, é saber, que devem sempre ser tomados segundo a sua máxima efetividade, é fácil perceber que, detendo os mesmos tal qualidade, possuem limitações externas, como o é a reserva do possível, podendo todos, direitos defensivos ou prestacionais, ser confrontados, quando colidentes nos casos concretos, segundo a regra da ponderação, prevalecendo topicamente o princípio que tiver maior peso, consideradas as condições da respectiva questão concreta, o que não quer dizer seja o direito fundamental escolhido, diante da escassez de recursos e possibilidades de escolha, prevalente sempre, tendo-se que as condições postas determinam o resultado em um ou outro sentido.

Melhor explicando, se os recursos estatais são escassos, cabe inicialmente ao Legislador decidir, segundo a escala de prioridades, qual direito 
fundamental será materialmente protegido, de acordo com os critérios de ponderação, observando-se a reserva do possível, que funciona sempre como limite à escolha em um ou outro sentido. Não sendo atendido o objetivo protetivo, cabe ao Judiciário a análise do caso concreto, estabelecendo novamente juízo de ponderação, dessa feita com diversos testes de constitucionalidade e sem ignorar o fato de que o procedimento de escolha anterior igualmente encontra fundamento em prioridades tidas pelos demais Poderes e que, portanto, não pode ser posto de lado sem mais.

É certo, porém, que, em se tratando de direitos fundamentais sociais prestacionais, a reserva do possível funciona como um limite sempre presente, pois eles são prevalentemente de dimensão positiva, comportando custo estatal maior, e a análise da sua viabilidade ou não é prefacialmente perpetrada pelo Legislador, cuja priorização orçamentária deve ser respeitada pelo Juiz.

Os recursos sempre existem, sempre há dinheiro em caixa, mas a escolha sobre onde o numerário deverá ser aplicado de forma prioritária é efetuada pelo Legislador, cabendo ao Estado-Juiz "apreciar se a dificuldade financeira alegada pelo poder político é suficientemente relevante, do ponto de vista do interesse público, para afastar ou fazer ceder a pretensão individual" e se a escolha efetuada e fundamentada "não merecem censura jurídicoconstitucional, controlos esses a que, do outro lado da questão, não é indiferente a importância ou premência de realização do respectivo direito social"177.

É dizer, a escolha feita pelo Legislador, diante da escassez de recursos estatais, deve ser respeitada pelo Juiz, não cabendo a este substituir a escolha feita anteriormente pela sua própria, pois, assim agindo, esbarra no princípio da separação dos poderes. Apenas quando a escolha efetuada pelo Estado-Legislador se mostrar incabível diante das prioridades estatais tidas no caso concreto posto em Juízo, é que caberá a intervenção judicial no sentido de se fornecer a prestação social pretendida ${ }^{178}$.

\footnotetext{
${ }^{177}$ NOVAIS, Jorge Reis. Op. cit., p. 117.

${ }^{178}$ Nesse sentido: "Uma vez que compete constitucionalmente ao poder político democraticamente legitimado definir prioridades e fazer escolhas no domínio da afectação dos recursos disponíveis - isto é, concretizar a reserva que afecta os direitos sociais -, então ao juiz só é reconhecida a última palavra se ele puder apurar, sem infracção do princípio da separação de poderes, portanto, sem usurpar as competências de definição e escolha orçamentais, que, apesar da reserva do possível que afecta os direitos sociais, o poder político ou a administração poderiam e deveriam fornecer a prestação social controvertida sob pena de violação do direito
} 


\section{Os direitos sociais prestacionais como direitos subjetivos}

Os Direitos Sociais prestacionais (ao trabalho, educação, saúde, moradia, lazer, segurança, alimentação, previdência social, assistência aos desamparados e proteção à maternidade e à infância) previstos no $\operatorname{artigo~} 6^{\circ}$ da nossa Constituição, por possuírem conteúdo indeterminado, não especificamente previsto já no Texto Constitucional, suscitam pertinente questionamento acerca da justiciabilidade e da possibilidade de serem tais Direitos subjetivos, tendo-se que, diante da característica já denotada, cabe ao legislador ordinário a fixação dos parâmetros do usufruto e alcance dos mesmos.

Os direitos de defesa não raramente são apontados pela doutrina ${ }^{179}$ como direitos mais palpáveis do ponto de vista da positivação, pois a técnica utilizada na confecção deles é mais direta, não comportando forte intervenção legislativa no sentido da sua limitação e alcance, enquanto os direitos sociais prestacionais, por serem indeterminados e não esmiuçados na Constituição, comumente necessitam de grande intervenção legislativa, pois a técnica de redação utilizada no Texto Constitucional não é capaz de abarcar todas as vicissitudes que comportam a proteção de ditos direitos, até porque não poderia fazê-1o, diante da dinâmica social, que gera um imenso risco de mudança de estrutura normativa, fazendo ensejar insegurança e constante modificação constitucional.

Aponta também a doutrina que os direitos de defesa, por não reclamarem, em regra, concretização legislativa, são direitos absolutos, ao passo que os direitos sociais prestacionais, por necessitarem não só da aludida concretização, mas habitualmente estarem vinculados à reserva do possível, são tidos como direitos relativos, tese que se afigura equivocada, pois não há um só direito fundamental absoluto ${ }^{180}$.

Questão que primeiro deve ser analisada é a pertinente à natureza jurídica das normas ordinárias que concretizam direitos fundamentais sociais prestacionais, como as que tratam de saúde, previdência e educação, que, mesmo não estando formalmente em um Texto Constitucional, podem ser tidas como

social, seja por força da irrelevância da questão financeira, seja por força da extrema premência e urgência de realização do direito social” (NOVAIS, Jorge Reis. Op. cit., p. 118).

${ }^{179}$ Cf. SARLET, Ingo Wofgang. Op. cit., p. 257.

${ }^{180}$ Cf. SARLET, Ingo Wolfgang. Op. cit., p. 290. 
materialmente fundamentais, tendo-se em vista que tratam justamente de direitos fundamentais, embora em patamar ordinário.

Os direitos sociais, visualizados segundo a sua dimensão principal, que é a prestacional, em geral, padecem de determinabilidade na Constituição. É dizer, a norma constitucional não institui, em termos definitivos, todas as peculiaridades dos aludidos direitos, cabendo ao legislador ordinário fazê-lo, sendo as normas infraconstitucionais, nesse particular, normas fundamentais, pela abertura do catálogo presente no artigo $5^{\circ}, \S 2^{\circ}$ da Constituição Federal de 1988.

Diante desse conteúdo de indeterminação, habitualmente os direitos sociais prestacionais, por se vincularem mais fortemente à reserva do possível, são tidos pela doutrina ${ }^{181}$ como direitos não subjetivos (concepção negativista), não concordando Novais com tal assertiva, assegurando que a característica da indeterminabilidade, embora atrelada à reserva do possível, estimula o legislador constituinte a fixar, "apenas um dever jurídico de realização do direito social de forma gradual e diferida no tempo por parte do Estado", assim como também remete "implicitamente para o legislador ordinário a fixação das prestações devidas no cumprimento dessa obrigação em função das disponibilidades e das circunstâncias de cada momento" ${ }^{182}$.

Por intermédio da atuação do legislador ordinário, fixando, com precisão e firmeza, o conteúdo do direito fundamental, este é concretizado e tornado definitivo. É o que a doutrina germânica ${ }^{183}$ intitulou de direitos sociais prestacionais derivados, cuja acepção como direito subjetivo e fundamental é defendida mais uma vez por Novais, quando, em sua obra, afiança:

os direitos sociais são direitos fundamentais, de conteúdo em grande medida indeterminado no plano constitucional, mas determinável através da actuação conformadora e concretizadora do legislador ordinário; na medida em que cumpram e enquanto cumpram essa função de realização dos direitos constitucionais sociais, os chamados direitos a prestações derivadas de criação legal são direitos fundamentais ou, mais rigorosamente, são faculdades, pretensões ou direitos particulares integráveis no

\footnotetext{
${ }^{181}$ Novais (op. cit., p. 87) cita os principais impedimentos, normalmente apontados doutrinariamente, para que os direitos sociais sejam tidos como subjetivos: "a) o facto de os direitos sociais valerem sob reserva do (financeiramente) possível; b) o facto de os direitos sociais apresentarem uma estrutura de direitos positivos; e c) a indeterminabilidade do conteúdo constitucional dos direitos sociais".

182 Op. cit., p. 152.

${ }^{183}$ Por todos: ALEXY, Robert. Op. cit., p. 442 e ss.
} 
direito fundamental como um todo, ou seja, o direito fundamental que tem como referência normativa a disposição constitucional consagradora do direito social.

Mais adiante, o referido autor parece se manifestar a respeito da vinculação dos direitos sociais a prestações como direitos subjetivos, quando analisa que a distinção entre direitos sociais prestacionais derivados e originais perde importância na Constituição de Portugal e na do Brasil, que tratam "indiferentemente uns e outros" ${ }^{184}$, sendo possível concluir que tanto há direito social prestacional subjetivo retirado da própria constituição, quanto previsto na própria lei ordinária.

A concepção de direitos prestacionais derivados como subjetivos em nada discrepa da tese clássica, segundo a qual a Constituição é um mero documento político, traçando conceitos indeterminados e um convite ao Legislador, sendo considerados direitos subjetivos apenas as normas ordinárias atinentes aos direitos constitucionais - máxime direitos fundamentais -, mas não as presentes na própria Constituição.

Como já analisado ao norte, o Constitucionalismo instituído a partir da segunda metade do século passado não aceita mais a supremacia da legislação ordinária em detrimento das normas presentes na Constituição, hoje tida não só como ordem de valores, mas capaz de encerrar direitos subjetivos, já retirados diretamente de seu próprio texto, mesmo que se tratem de direitos sociais, interessando mais o modo como está redigido o dispositivo constitucional, para que se tenha acerca da sua densidade normativa.

Todavia, uma coisa é certa: ao Judiciário não cabe mais tomar as normas sociais prestacionais como meros lembretes de que um dia o Legislador, quando assim o desejar, concretizará o direito e que até lá há um hiato intransponível ao Estado-Juiz.

A missão hoje posta pela Constituição, enquanto sistema de valores, é a vinculação direta do Estado-Juiz ao próprio Texto da Constituição, cabendo-lhe a interpretação que mais estimule eficácia à norma jusfundamental, para que o seu conteúdo não reste esvaziado e sem valor.

Pensar o contrário é permanecer na interpretação ortodoxa de que o Judiciário é a “boca da Lei”, quando até infraconstitucionalmente há previsão

${ }^{184}$ NOVAIS, Jorge Reis. Op. cit., p. 162, nota de rodapé n. 180. 
de que na falta de previsão legal, sejam os princípios ${ }^{185}$ (hoje concebidos como normas) utilizados no julgamento, para que seja alcançado ao máximo o escopo protetivo estatal.

Esse parece ser também o entendimento de Bandeira de Mello, quando, ao analisar os princípios regentes da Ordem Econômica e Social na Constituição, afiança que tais "não chegam a conferir aos cidadãos uma utilidade substancial, concreta, desfrutável positivamente e exigível quando negada", sendo, no entanto, fontes de direitos, pois podem: “a) proporcionar aos administrados a possibilidade de se oporem judicialmente ao cumprimento de regras e à prática de comportamentos adversos ao estatuído na Carta do país”, assim como "b) imporem ao Judiciário, quando da interpretação e dicção do Direito nos casos concretos, decisões que convirjam na mesma direção e sentido destes preceitos"186.

Quando alude ao salário mínimo, com previsão constitucional no artigo $7^{\circ}$, IV, o citado publicista parece conceber a possibilidade de se retirar desse direito social um direito subjetivo, quando há omissão do Legislador, ou norma que não atende aos fins previstos no próprio dispositivo legal, levando a crer que o grande problema dos direitos sociais não é a vinculação à tese da eficácia direta ou não, substantiva ou objetiva, mas sim o modo como o direito fundamental está constitucionalmente positivado, tendo-se que, em relação ao salário mínimo, já há um dever imposto pela Constituição de que todos aqueles fins sociais sejam preenchidos com o valor do salário, e quando o EstadoLegislador não logra cumprir a sua missão imposta pelo Legislador Constituinte, cabe ao Estado-Juiz a fixação de indenização para suprir tal carência $^{187}$. Nesse particular, é mais correto se falar em ofensa a um dever de proteção, decorrente mesmo do direito prestacional de forma ampla ${ }^{188}$.

Eros Grau vai além, considerando os direitos sociais prestacionais como direitos subjetivos, diante da cláusula do artigo $5^{\circ}, \S 1^{\mathrm{o}}$ da nossa Constituição, devendo o Poder Judiciário, por força do inciso XXXV do mesmo

\footnotetext{
${ }^{185}$ Artigo $4^{\text {o }}$ da Lei de Introdução ao Código Civil.

186 Op. cit., p. 48.

187 Op. cit., p. 49.

188 Sobre o dever de proteção, vedação à insuficiência e papel do Estado-Juiz: VALE, Silvia Isabelle Ribeiro Teixeira do. Participação nos lucros e resultados: uma abordagem à luz do dever de proteção. In: Revista LTr. Legislação do Trabalho, v. 12, p. 78-12/1468, 2014.
} 
artigo, assegurar, no caso concreto, a viabilidade do objeto da prestação, por meio da analogia, do costume ou dos princípios gerais do Direito ${ }^{189}$, entendimento que, embora se afigure como bastante sedutor (até porque encerraria toda a presente análise), não se apresenta como o mais acertado.

$\mathrm{Na}$ doutrina estrangeira, encontra-se a lição de Abramovich e Courtis, ambos asseverando que os Direitos Sociais prestacionais são direitos subjetivos e, portanto, exigíveis, sendo mais relevante falar em "níveis de obrigações estatais" 190 para todos os direitos fundamentais, já que todos possuem a mesma estrutura quando avistados sob a ótica positiva ou negativa de prestação estatal, bem como da reserva do possível ${ }^{191}$.

Nesse contexto, afirmam os autores aludidos que os níveis vinculantes de obrigações em relação aos Direitos Fundamentais são: obrigações de respeito, obrigações de proteção e obrigações de satisfação, sendo todos os direitos, civis, políticos, sociais, culturais e econômicos, compostos de um "complexo de obrigações positivas e negativas" 192.

Embora sem se reportar diretamente, os citados autores se aproximam muito das lições de Alexy quando afiançam que as obrigações positivas do Estado não se esgotam na discussão acerca da existência ou não de fundos (reserva do possível), pois há direitos que "se caracterizam pela obrigação de o Estado estabelecer algum tipo de regulação, sem a qual o exercício de um direito não tem sentido", ou em outros casos, a obrigação estatal é somente no sentido de regulação ou limite das atividades ou faculdades dos particulares, como ocorre na limitação da jornada de trabalho, fixação do salário mínimo e proteção contra a despedida arbitrária ${ }^{193}$, no que os autores aproximam mais ainda os direitos sociais prestacionais (no sentido de prestação jurídica) aos direitos de defesa, tendo-se que, nesse particular, há uma estipulação mínima ou máxima, uma limitação - ou defesa - às atividades do

189 GRAU, Eros Roberto. A ordem econômica na Constituição de 1988. 15. ed., São Paulo: Malheiros, 2012, p. 318.

190 ABRAMOVICH, Victor; COURTIS, Christian. Direitos sociais são exigíveis. Trad. Luis Carlos Stephanov, Porto Alegre: Ed. Dom Quixote, 2011, p. 37.

${ }^{191}$ Em idêntico sentido: "não haverá dúvida quanto aos direitos, liberdades e garantias, cujos preceitos gozam, por determinação constitucional, de aplicabilidade directa, mas o conceito também se aplica aos próprios direitos sociais a prestações" (ANDRADE, José Carlos Vieira de. Os direitos fundamentais na Constituição portuguesa de 1976. 4. ed., Coimbra: Almedina, 2009, nota de rodapé n. 20, p., 113).

192 Op. cit. p. 40-41.

193 Op. cit. p. 45. 
próprio Estado ou de particulares, confirmando, com isso, a irrelevância de se traçarem grandes diferenças deônticas em relação aos direitos sociais e de defesa, sendo ambos direitos subjetivos.

Sem embargo, classicamente todos os direitos de defesa - ou preponderantemente defensivos, para que fique mais claro - são considerados direitos subjetivos, terminologia que encontrou na obra de Jellinek seu ápice, quando este publicista tratou dos status do indivíduo em relação ao Estado.

Não poderia ser diferente, já que no final do século XIX, início do século XX, sequer se pensava seriamente na existência de um Estado Social, o que somente ocorreu após a segunda metade do século passado, havendo até quem entenda que pensar os direitos sociais como direitos subjetivos atenta contra a natureza das coisas, pois é "natural" que se pense em direitos de liberdade como inatos ao Homem e "não natural", ou uma mera criação artificial do ser humano, pensar em direitos sociais como direitos subjetivos ${ }^{194}$, o que é mera retórica, pois os direitos sociais são, na verdade, uma evolução do próprio Estado Liberal, que precisou se reinventar para atender a uma demanda social premente, desejada pela sociedade que deixava de ser individual e passava a ser massificada.

Direitos como saúde, educação, consumidor, cultura, somente para citar alguns, passaram a ser requisitados e necessários para o próprio estabelecimento do que se consolidou chamar de liberdade no sentido material, e o Estado, antes inimigo, passou a ser o grande realizador dos direitos fundamentais (agora sociais), para que tal igualdade fosse alcançada.

Nesse contexto, é visível que todos os direitos fundamentais, no fim, são de liberdade, e os direitos sociais a prestações são apenas uma pequena parcela desse modo novo de agir estatal, sendo certo que, no contexto do Estado Social, o indivíduo possui não só direito a prestação material, mas também a prestação jurídica, de não ser discriminado (direito derivado a prestação), acepções estas que se aproximam da noção defensiva do Estado, denotando que todos os direitos, sociais ou de defesa, são subjetivos, variando apenas o grau

${ }^{194}$ Cf. NOVAIS, Jorge Reis. Op. cit., p. 141 e ABRAMOVICH, Victor; COURTIS, Christian. Op. cit., p. 2829. 
de densidade normativa dos mesmos e como cada um pode ser amplificado ou deixado temporariamente de lado à luz da ponderação de interesses colidentes.

Nesse mesmo sentido é a lição de Sarlet, para quem "o problema apenas poderá ser equacionado à luz das circunstâncias do caso concreto e do direito fundamental específico em pauta, sendo indispensável a ponderação dos bens e valores em conflito". É dizer:

\begin{abstract}
em todas as situações em que o argumento da reserva de competência do legislador (assim como a separação de poderes e as demais objeções habituais aos direitos sociais a prestações como direitos subjetivos) implicar grave agressão (ou mesmo o sacrifício) do valor maior da vida e da dignidade da pessoa humana, ou nas hipóteses em que, da análise dos bens constitucionais colidentes, resultar a prevalência do direito social prestacional, poder-se-á sustentar que, na esfera de um padrão mínimo existencial, haverá como reconhecer um direito subjetivo definitivo a prestações, admitindo-se, onde tal mínimo for ultrapassado, tão-somente um direito subjetivo "prima facie", já que - nesta seara - não há como resolver a problemática em termos de uma lógica do tudo ou nada ${ }^{195}$.
\end{abstract}

Em obra de maior impacto, novamente Sarlet ${ }^{196}$ voltou a afirmar que todos os direitos fundamentais sociais (prestacionais ou não) são direitos subjetivos, mas tal certeza não encerra a questão, somente resolvida, na prática, com a ponderação de interesses fundamentais constitucionalmente assegurados, não havendo razão para a argumentação séria sobre a reserva do possível fática ou a (in)competência dos Tribunais para a análise dos problemas atinentes às prestações sociais (reserva do possível jurídica), devendo a discussão versar muito mais sobre o não esvaziamento dos direitos sociais - que não são meras metas políticas traçadas na Constituição, e sim reais direitos subjetivos -, devendo o sopesamento passar necessariamente pela análise do mínimo existencial, assim entendido como a dignidade da pessoa humana ${ }^{197}$ e o próprio

\footnotetext{
195 SARLET, Ingo Wolfgang. Os direitos fundamentais sociais na Constituição de 1988. In: Revista Diálogo Jurídico. Salvador: CAJ, n. 1, abril/2001, p. 37.

${ }^{196}$ SARLET, Ingo Wolfgang. A eficácia dos direitos fundamentais. Op. cit., p. 342 e ss.

${ }^{197}$ Com a proposta de delimitação do conteúdo do princípio da dignidade da pessoa humana, Soares afiança que "dignidade humana é um constructo cultural fluido e multiforme, que exprime e sintetiza, em cada tempo e espaço, o mosaico dos direitos humanos fundamentais, num processo expansivo e inexaurível de realização daqueles valores da convivência humana que melhor impedem o aviltamento e a instrumentalização do ser humano" (SOARES, Ricardo Maurício Freire. O princípio da dignidade da pessoa humana. São Paulo: Saraiva, 2010, p. 144).
} 
direito à vida, não podendo o Estado Social de Direito ser excessivo, nem muito menos insuficiente.

\section{As liberdades sociais}

Não é incomum encontrar na doutrina classificação que apõe todos os direitos sociais no patamar de direitos prestacionais ${ }^{198}$, pois estes somente passaram a fazer parte das Constituições com o advento do Estado Social, o que parece ser pouco acertado.

O Estado Liberal clássico fundamentava-se na concepção dos sujeitos como indivíduos, que, por serem formalmente iguais, poderiam contratar livremente, pois o próprio mercado ditava as suas regras, sempre fundadas na autonomia da vontade, que, selada por meio de vinculação contratual, figurava como verdadeira "lei entre as partes".

Nesse contexto, ao Estado cabia tão só o afastamento das relações privadas, criando regras no sentido de assegurar às partes convenentes o livre exercício da autonomia sem limitações. Não é difícil compreender que, durante tal período, os primeiros Direitos Fundamentais, antes tidos como "naturais" uma vez que decorrentes do jusnaturalismo, e "reconhecidos" pelas novas codificações - passaram a ser positivados também através de documentos constitucionais, que tinham como objetivo assegurar a plenitude da propriedade e do direito à liberdade e que, por conta disso, foram concebidos sob a ótica negativista do Estado, cuja missão somente consistia em assegurar a plenitude de seu afastamento das relações firmadas entre os indivíduos.

O modelo do Estado Social surge não abandonando a modelagem já posta, mas substitui o paradigma firmado com o Estado Liberal, tendo-se que este, fundado no protótipo da igualdade entre os indivíduos, na prática, gerava um abismo de desigualdade.

Com o surgimento da sociedade de massa, as necessidades também se amplificaram e o direito teve que se reinventar e, se antes se idealizava abstratamente o ser humano como formalmente igual, a realidade mostrou que

\footnotetext{
${ }^{198}$ De acordo com Abramovich (op. cit., p. 31), as classificações que inserem todos os direitos de liberdade como direitos de defesa e os de prestação como sociais, "estão baseadas numa visão totalmente parcial e 'naturalista' do papel e fucionamento do aparato estatal, que coincide com a posição antiquada de um Estado mínimo que garanta exclusivamente a justiça, a segurança e a defesa”.
} 
a liberdade plena mais escravizava do que libertava, sendo necessária uma intervenção legislativa protetiva e "desigual” para proteger o indivíduo, agora enxergado de forma concreta, havendo uma necessidade de fixação estatal de limites para a contratação.

O Estado passa de abstencionista para intervencionista e, nesse cenário, a classificação dos Direitos Fundamentais, que até então eram ligados à atividade estatal negativa, evoluiu para considerar esses "novos direitos" como direitos positivos, de prestação estatal.

Se é correto afirmar que o Estado Liberal e a função estatal abstencionista não foram totalmente ultrapassados pelo surgimento do Estado Social, não menos correto é afirmar que nem todos os direitos sociais figuram como reais direitos a prestações, sendo certo que há direitos sociais que são verdadeiros direitos de liberdade, a exemplo de boa parte do rol dos direitos fundamentais sociais dos trabalhadores, como o direito ao salário mínimo; irredutibilidade do salário; limitação da jornada de trabalho em oito horas, ou módulo semanal de quarenta e quatro horas; proibição de diferença de salários, de exercício de funções e de critério de admissão por motivo de sexo, idade, cor ou estado civil; proibição de qualquer discriminação no tocante a salário e critérios de admissão do trabalhador portador de deficiência e proibição de distinção entre trabalho manual, técnico e intelectual ou entre os profissionais respectivos; todos com previsão no artigo $7^{\circ}$ do Texto Constitucional.

Nesse trilhar, concordando que os Direitos Fundamentais Sociais não se encerram na sua função prestacional, Sarlet já asseverou que grande parte dos direitos dos trabalhadores, presentes nos artigos $7^{\circ}$ a 11 da nossa Constituição, "são, na verdade, concretizações do direito de liberdade e do princípio da igualdade (ou da não-discriminação), ou mesmo posições jurídicas dirigidas a uma proteção contra ingerências por parte dos poderes públicos e entidades privadas" ${ }^{199}$, deixando evidenciado que, no rol aludido assim como nos demais dispositivos que tratam de Direitos Sociais, há direitos prestacionais e direitos de defesa, sendo mais coerente tratar estes últimos como "liberdades sociais".

${ }^{199}$ SARLET, Ingo Wolfgang. A eficácia dos direitos fundamentais. Op. cit., p. 174. 
$\mathrm{Na}$ doutrina de Hermano Queiroz Júnior também se encontra presente a mesma conclusão, tendo o referido autor já pontificado que, dentre os direitos sociais elencados nos artigos $6^{\circ}$ a 11 da Constituição Federal de 1988, “muitos há que não se acham contemplados dentro do grupo de direitos fundamentais à prestação, mas, ao reverso, se enquadram no grupo dos direitos de defesa, na medida em que ostentam o caráter de direitos à abstenção" 200 , citando praticamente os direitos sociais trabalhistas defensivos já aludidos ao norte.

No artigo $8^{\circ}$ da Lei Fundamental pátria é clara a previsão de legítimos direitos de liberdade, que são o direito de greve ${ }^{201}$, a liberdade e autonomia sindical, embora capitulados no rol dos Direitos Sociais, demonstrando que o Legislador Constituinte não discrepou entre colocar direitos prestacionais e de liberdade no capítulo dos Direitos Sociais do trabalhador, não fazendo qualquer distinção em relação à eficácia entre os mesmos, até porque não poderia, diante da cláusula presente no artigo $5^{\circ}, \S 1^{\circ}$ da nossa Constituição.

Idêntica manifestação se mostrava na Constituição Portuguesa de 1976 em sua versão originária, onde diversos dos direitos fundamentais dos trabalhadores, inicialmente postos no título dos direitos econômicos, sociais e culturais, passaram a ser, a partir da revisão de 1982 , elencados no título dos direitos, liberdades e garantias ${ }^{202}$, tendo Sarlet atentado para o fato de que "esta categoria de direitos fundamentais sociais, de cunho notoriamente negativo, tem sido oportunamente denominada de 'liberdades sociais' ${ }^{203}$, integrando o que se

\footnotetext{
${ }^{200}$ QUEIROZ JÚNIOR, Hermano. Os direitos fundamentais dos trabalhadores na Constituição de 1988 , São Paulo: LTr, 2006, p. 67.

${ }^{201}$ Lançando luzes sobre a tese ora defendida, a doutrina de Martinez: "nenhum direito fundamental, entretanto, é, em rigor, unicamente defensivo ou prestacional. O seu exercício não pode acontecer sem que ações negativas e positivas sejam cumulativamente exigidas. Exatamente assim ocorre com o instituto da liberdade sindical, em nome do qual estão agregados todos os direitos que viabilizam a proteção do patrimônio jurídico dos trabalhadores, entre os quais o direito de greve e o de negociar coletivamente. Apesar de serem posições fundamentais subjetivas de natureza defensiva, notadamente quando opostas contra o Estado, comportam, sem dúvidas, múltiplas faculdades de exigir ou de pretender ações positivas, seja para a promoção das condições de seu gozo efetivo, seja para a sua proteção contra terceiros" (MARTINEZ, Luciano. Condutas antissindicais. São Paulo: Saraiva, 2013, p. 124).

${ }^{202}$ Cf. SARLET, Ingo Wolfgang. Os direitos fundamentais sociais na Constituição de 1988. In: Revista Diálogo Jurídico. Salvador: CAJ, n. 1, abril/2001, p. 18.

203 Como pontifica ANDRADE, José Carlos Vieira de. Os direitos fundamentais na Constituição portuguesa de 1976, 4. ed., Coimbra: Livraria Almedina, 2007, p. 385, quando faz remissão às liberdades sociais presentes na Constituição portuguesa, indicando o direito de greve e a liberdade sindical como legítimos representantes das ditas liberdades.
} 
poderia chamar - inspirados na concepção de Jellinek - de um 'status negativus socialis' ou 'status socialis libertatis",204.

Nesse mesmo passo, assegura Cristina Queiroz que a Constituição portuguesa de 1976 atualmente qualifica como "liberdades e garantias" - ou, simplesmente, liberdades sociais, pela doutrina - determinados direitos dos trabalhadores, verdadeiras pretensões defensivas, a exemplo do direito de greve e da liberdade sindical, antes da aludida reforma apenas tidos como meros direitos sociais ${ }^{205}$.

Miranda, após afirmar que a designação complexa de direitos, liberdades e garantias não é corrente no estrangeiro, assevera que a liberdade sindical e o direito de greve, previstos respectivamente nos artigos $55^{\circ}$ e $57^{\circ}$ da Constituição portuguesa de 1976, são legítimos exemplos de liberdades ${ }^{206}$.

Sem embargo, como já verificado ao norte, todos os Direitos Fundamentais, de defesa ou sociais (prestacionais ou não) são de liberdade ${ }^{207}$, pois é impossível o indivíduo alçar qualquer patamar socialmente justo e digno ${ }^{208}$ sem que lhe sejam assegurados direitos mínimos pelo Estado, tanto é assim que, em regimes constitucionais onde não se tem um rol de direitos sociais, a própria jurisprudência se encarregou de firmar determinadas tarefas estatais, como o fez o Tribunal Constitucional alemão, com a noção de "mínimo existencial", já que a Lei Fundamental de 1949 praticamente não trata de Direitos Sociais.

Isso é algo até curioso, já que em terras germânicas a referida Corte extraiu do direito à vida e do princípio da dignidade da pessoa humana a construção sobre o mínimo existencial e aqui, em terras brasileiras, mesmo com um imenso rol de direitos sociais prestacionais e de defesa, a doutrina e a

\footnotetext{
${ }^{204}$ SARLET, Ingo Wolfgang. Os direitos fundamentais sociais na Constituição de 1988. In: Revista Diálogo Jurídico. Salvador: CAJ, n. 1, abril/2001, p. 18.

205 QUEIROZ, Cristina M. M. Direitos fundamentais sociais. Funções, âmbito, conteúdo, questões interpretativas e problemas de justiciabilidade. Coimbra Editora, 2002, p. 27.

${ }^{206}$ MIRANDA, Jorge. Manual de Direito Constitucional. Tomo IV, 2, ed., Coimbra: Coimbra Editora, 1993 , p. 93.

207 "No existen derechos de liberdad, por um lado, y derechos de igualdad, por outro: todos los derechos son de liberdad, incluso aquéllos que aportan un elemento igualitario, como es el caso de los económicos y sociales, al potenciar y reforzar dicho elemento la liberdad para todos. [...] Por ello, al analizar la estructura de los derechos soiales, se comprueba - aunque persistan notables rasgos distintivos - la inexistencia de uma fractura radical com los tradicionales derechos de liberdad" (IBARRECHE, Rafael Sastre. EI derecho al trabajo. Madrid: Editora Trotta, 1996, pp. 71-72).

${ }^{208}$ Nesse tocante, Gabriela Neves Delgado atesta que o direito ao trabalho, sobretudo o direito ao trabalho digno faz parte desse patamar mínimo (Direito fundamental ao trabalho digno, São Paulo: LTr, 2006).
} 
jurisprudência ainda relutam em creditar plena eficácia a alguns direitos, como, por exemplo, o direito ao trabalho, assim compreendido como direito subjetivo não a um posto de trabalho, mas sim, pelo menos, como respeito ao posto ativo de trabalho, não podendo o empregado ser despedido sem que haja um motivo.

Essa também é a doutrina de Jorge Miranda, para quem, ao revés de existir uma separação estanque entre direitos negativos e direitos positivos, há intercomunicação entre eles, pois, enquanto o paradigma liberal pregava a liberdade abstrata, a ideia presente no modelo social não despreza a liberdade, mas entende que esta somente é alcançada com a igualdade material entre os indivíduos, mediante forte intervenção estatal, pois:

igualdade material não se oferece, cria-se; não se propõe, efectiva-se; não é um princípio, mas uma consequência. O seu sujeito não a traz como qualidade inata que a Constituição tenha de confirmar e que requeira uma atitude de mero respeito; ele recebe através de uma série de prestações, porquanto nem é inerente às pessoas, nem preexiste ao Estado. Onde bastaria que o cidadão exercesse ou pudesse exercer as próprias faculdades jurídicas, carece-se doravante de actos públicos em autónoma discricionariedade. Onde preexistiam direitos, imprescindíveis, descobrem-se condições externas que se modificam, se removem ou se adquirem. Assim, o conceito de direito à igualdade consiste sempre num comportamento positivo, num facere ou num dare ${ }^{209}$.

Se se observar atentamente o Capítulo II do Texto Constitucional, facilmente se perceberá que a própria Lei Fundamental estabeleceu uma limitação, um patamar mínimo, fixando diretrizes que deverão ser cogentemente observadas quando da pactuação empregatícia, sendo correto afirmar que abaixo do patamar estabelecido constitucionalmente, não é possível qualquer contratação individual.

No tocante à negociação coletiva, a Carta Política foi mais benevolente, permitindo que alguns direitos pontuais, a exemplo do salário e da jornada de trabalho, possam ser pactuados pelos sindicatos, em pleno exercício da autonomia privada coletiva. Assim, é possível afirmar que a limitação firmada na Constituição pátria é total em relação às partes individualmente, mas relativa em termos coletivos ${ }^{210}$.

\footnotetext{
${ }^{209}$ MIRANDA, Jorge. Op. cit., p. 96-97.

${ }^{210}$ Eis a lição de Maurício Godinho Delgado: "não prevalece a adequação setorial negociada se concernente a direitos revestidos de indisponibilidade absoluta (e não indisponibilidade relativa), os quais não podem ser transacionados nem mesmo por negociação sindical coletiva. Tais parcelas são aquelas imantadas por uma
} 
Mais acertado ainda parece afirmar que dito patamar constitucional mínimo figura como verdadeiro direito defensivo, não podendo sequer ser o seu espectro protetivo diminuído, por força do caput do artigo $7^{\circ}$ da nossa Constituição, segundo o qual todo o rol que se segue é apenas exemplificativo, pois outros direitos sociais do trabalhador poderão ser previstos ordinariamente, não podendo haver alteração a menor, significando dizer que há uma barreira estatal, uma defesa em face de alterações in pejus, mais próxima ao direito de liberdade do que ao prestacional ${ }^{211}$.

\section{Conclusão}

Como analisado, as normas constitucionais tratantes de direitos fundamentais sociais são atreladas ao princípio da reserva do possível tanto quanto os direitos de liberdade e as próprias liberdades sociais, que seguem a lógica de abstenção estatal de forma preponderante. É dizer, todos os direitos constitucionais, de liberdade ou sociais prestacionais, são direitos subjetivos e possuem eficácia, sendo muito mais relevante observar a técnica utilizada pelo Estado-Legislador, para saber se no caso concreto o direito padece de alta ou baixa densidade normativa.

\section{Referências}

ABRAMOVICH, Victor; COURTIS, Christian. Direitos sociais são exigíveis. Trad. Luis Carlos Stephanov, Porto Alegre: Ed. Dom Quixote, 2011.

AMARAL, Gustavo. Direito, Escassez \& Escolha. Critérios Jurídicos para Lidar com a Escassez de Recursos e as Decisões Trágicas. 2. ed. Rio de Janeiro: Renovar, 2010.

CAnotilho, J. J. Gomes. Direito Constitucional e Teoria da Constituição. 5. ed., Coimbra: Almedina, 2002.

tutela de interesse público, por se constituírem em um patamar civilizatório mínimo que a sociedade democrática não concebe ver reduzido em qualquer segmento econômico-profissional, sob pena de se afrontarem a própria dignidade da pessoa humana e a valorização mínima deferível ao trabalho" (Introdução ao direito do trabalho: relações de trabalho e relação de emprego. 2. ed., São Paulo: LTr, 1999, p. 197).

${ }^{211}$ Fábio Rodrigues Gomes (O Direito Fundamental ao Trabalho, Rio de Janeiro: Lumen Juris Editora, 2008, p. 178), dissertando acerca das diversidades atinentes ao direito de defesa e ao direito à proteção, assevera que não se deve confundir a função defensiva dos direitos fundamentais com a categoria dos direitos de defesa, pois "a primeira é inerente a qualquer direito fundamental e implica, não a exclusão do Estado, mas, sim, a sua intervenção (subsidiária) em determinadas hipóteses [...]. A segunda, representa os direitos de liberdade voltados contra o Estado, bloqueando normativamente a sua intervenção indevida". 
DELGADO, Maurício Godinho. Introdução ao direito do trabalho: relações de trabalho e relação de emprego. 2. ed., São Paulo: LTr, 1999.

GOMES, Fábio Rodrigues. Direito Fundamental ao Trabalho: Perspectivas Histórica, Filosófica e Dogmático-analítica. Rio de Janeiro: Lumen Juris Editora, 2008 .

GRAU, Eros Roberto. A ordem econômica na Constituição de 1988. 15. ed., São Paulo: Malheiros, 2012.

HESSE, Konrad. A força normativa da Constituição. Tradução de Gilmar Ferreira Mendes. Porto Alegre: Sergio Antonio Fabris Editor, 1991.

MARTINEZ, Luciano. Condutas antissindicais. São Paulo: Saraiva, 2013.

MELLO, Celso Antônio Bandeira de. Eficácia das normas constitucionais e direitos sociais. 1. ed., $3^{\text {a }}$ tiragem, São Paulo: Malheiros, 2011.

MOREIRA, Alinie da Matta. As restrições em torno da reserva do possível. Belo Horizonte: Editora Fórum, 2011.

NOVAIS, Jorge Reis. Direitos sociais. Teoria jurídica dos direitos sociais enquanto direitos fundamentais. Coimbra: Coimbra Editora, 2010.

QUEIROZ, Cristina M. M. Direitos fundamentais sociais. Funções, âmbito, conteúdo, questões interpretativas e problemas de justiciabilidade. Coimbra Editora, 2000.

QUEIROZ JÚNIOR, Hermano. Os direitos fundamentais dos trabalhadores na Constituição de 1988, São Paulo: LTr, 2006.

SARLET, Ingo Wolfgang. A eficácia dos Direitos Fundamentais: Uma teoria geral dos direitos fundamentais na perspectiva constitucional. 10. ed. Porto Alegre: Livraria do Advogado Editora, 2009.

. Os direitos fundamentais sociais na Constituição de 1988. In: Revista Diálogo Jurídico. Salvador: CAJ, n. 1, abril/2001.

SILVA, José Afonso da. Aplicabilidade das Normas Constitucionais. 7. ed., São Paulo: Malheiros, 2007. 
SOARES, Ricardo Maurício Freire. O princípio da dignidade da pessoa humana. São Paulo: Saraiva, 2010. 